\title{
ARTIGOS
}

\section{ATENDIMENTO EDUCACIONAL ESPECIALIZADO: ASPECTOS DA FORMAÇÃO DO PROFESSOR}

\section{MARA SILVIA PASIAN • ENICÉIA GONÇALVES MENDES • FABIANA CIA}

\section{RESUMO}

Estudos sobre a formação do professor de educação especial nas salas de recursos multifuncionais - SRM - são importantes para verificar o que está sendo viabilizado, as dificuldades encontradas e o que requer mais investimento. Este estudo teve por objetivo analisar a opinião dos professores de SRM em relação à sua formação. Utilizou-se um questionário on-line em larga escala, enviado a professores das SRM em âmbito nacional. Coletaram-se dados de 1202 professores de SRM de 20 estados, em mais de 150 municípios. A maioria dos participantes apontou a necessidade de outro profissional na SRM e falta de preparo. A formação foi destacada a fim de buscar aprimoramento de seus conhecimentos. Além disso, a maioria dos professores sente-se reconhecido pela escola e família.

FORMAÇÃO DE PROFESSORES • EDUCAÇÃO ESPECIAL • INCLUSÃO • SALA DE RECURSOS MULTIFUNCIONAIS

\section{SPECIALIZED EDUCATIONAL SERVICES:} ASPECTS OF TEACHER EDUCATION

\section{ABSTRACT}

Studies on the training of the special education teacher in multi-functional resource classes - MRC - are important because they verify what is being done, what are the difficulties faced and where more investment is required. This study aimed to analyze the opinions of MRC teachers regarding their training. A large scale, online questionnaire was submitted to MRC teachers nationwide. Data was collected from 1,202 teachers from 20 states and in more than 150 cities. Most participants highlighted both the need for a second professional in the MRC as well as the lack of preparation. Teachers pointed to training as a means of improving their knowledge. In addition, most teachers felt recognized by schools and families. 
RÉSUMÉ

Les études concernant la formation des professeurs d'éducation spéciale dans les salles de ressources multifonctionnelles - SMR - sont importantes pour vérifier ce qu'y est accompli, les difficultés rencontrées et où de plus grands investissements sont nécessaires. L'objectif de ce travail est d'analyser l'opinion des professeurs de SEM sur leur formation. Un questionnaire en ligne à éche11e nationale a recueilli les données de 1202 professeurs des SM de 20 différents états, et plus de 150 communes. La plupart des participants a souligné l'importance d'avoir un autre professionnel de SMR à leur côté, ainsi que le manque de préparation specialisée. La formation a été priorisée comme outil de perfectionnement de leurs connaissances. Par ailleurs, la plupart des professeurs declare se sentir reconnue par l'école et par les familles.

FORMATION DES ENSEIGNANTS • ÉDUCATION SPÉCIALE • INCLUSION • SALLE DE RESSOURCES MULTIFONCTIONNELLES

\section{ATENCIÓN EDUCACIONAL ESPECIALIZADA: ASPECTOS DEL PROFESOR \\ RESUMEN}

Los estudios sobre la formación de profesores de educación especial en las salas de recursos multifuncionales -SRM- son importantes para verificar qué se ha hecho viable, las dificultades encontradas y aquello que requiere más inversión. Este estudio tuvo el objetivo de analizar la opinión de los docentes de las SRM en cuanto a su formación. Se utilizó un cuestionario en línea a gran escala, enviado a los profesores de las SRM a nivel nacional. Se recogieron datos de 1202 docentes de las SRM de 20 estados, en más de 150 municipios. La mayoría de los participantes destacó la necesidad de haber otro profesional en la SRM y la falta de preparación. La formación se destinó a perfeccionar sus conocimientos. Además, la mayoría de los profesores se siente reconocida por la escuela y la familia. 


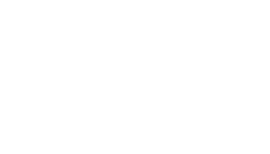

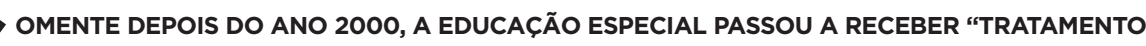
no campo da legislação e política educacional que nos permite afirmar a existência de um movimento na direção de lhe atribuir significado diferenciado dos anos anteriores" (PRIETO, 2010, p. 61). A partir de 2003, o Governo Federal implantou vários programas que, unidos a uma série de ações, objetivavam criar uma política de educação inclusiva (PRIETO, 2010; MENDES, 2006).

Em 2008, elaborou-se um documento oficial cujas diretrizes visavam à implantação dessa política. Esse documento, intitulado Política de educação especial na perspectiva da educação inclusiva - PEE-EI -, articulado aos programas propostos, indicou os rumos da educação especial no sentido de elaborar uma proposta de educação dentro da classe comum para alunos público-alvo da educação especial - PAEE (KASSAR, 2012). A PEE-EI indica que os alunos PAEE devem ser matriculados na classe comum, devendo frequentar o serviço de Atendimento Educacional Especializado - AEE - no contraturno (BRASIL, 2008b).

A partir de 2008, houve a criação de várias políticas que abordaram o serviço de AEE, o qual deve ser ofertado dentro das Salas de Recursos Multifuncionais - SRM -, colocando como dever dos sistemas de ensino garantir o acesso ao ensino comum e ao AEE aos educandos PAEE (BRASIL, 2011). É dentro desse contexto que se encaixa o presente trabalho, parte integrante do Observatório Nacional de Educação Especial - ONEESP -, uma rede de estudos de âmbito nacional cujo 
foco é discutir, em esfera nacional, o Programa de Implantação de Salas de Recursos Multifuncionais, promovido pela Secretaria de Educação Especial do Ministério da Educação - MEC.

Parte-se, neste estudo, do pressuposto que a atual política objetiva prover aos educandos PAEE acesso à classe comum. Ao mesmo tempo, compreende-se que esse acesso precisa vir acompanhado de permanência e, consequentemente, de sucesso escolar (PASIAN; VELTRONE; CAETANO, 2012). Nesse sentido, faz-se necessário refletir sobre a formação docente tanto no que tange ao professor da classe comum, quanto ao professor da SRM. No que se refere ao professor da classe comum, há um discurso constante de "não saber lidar" com o alunado PAEE, bem como de não estar devidamente preparado para lidar com a diversidade de seu alunado como um todo. Problemática essa que precisa ser debatida, pois um dos elementos-chave para o atendimento dos educandos PAEE é o professor (FERNANDEZ, 1998), demandando assim:

[...] uma postura e uma compreensão do fazer pedagógico que envolve uma análise crítica da organização escolar, reflexão e busca de conhecimentos constantes, por meio de discussão com seus pares e junto às fontes de conhecimento já sistematizadas. (VITALINO; VALENTE, 2010, p. 44)

A colaboração entre o professor da classe comum e o professor da SRM é uma possibilidade para minimizar as dificuldades encontradas pelo professor regular. Mas esse professor da SRM é suficientemente preparado para lidar com seu alunado? Em relação à legislação brasileira, a LDB (BRASIL, 1996), a Resolução CNE n. 2 (BRASIL, 2001), a PEE-EI (BRASIL, 2008a), a Resolução CNE/CEB n. 4 (BRASIL, 2009), dentre outras, assinalam que é importante se pensar a formação do professor, sobretudo sua formação continuada, objetivando criar possibilidades para que o aluno no serviço do AEE tenha suas necessidades educacionais consideradas e acesso a uma educação de qualidade.

Estudos que abordam a formação do professor de educação especial para o trabalho na SRM são essenciais para que seja possível verificar o que está sendo viabilizado e as dificuldades encontradas, para obter-se conhecimento sobre a nova realidade proposta na educação brasileira para os alunos da educação especial, o que precisa ser melhorado e o que requer mais investimento. Dessa forma, o presente estudo teve por objetivo analisar a opinião dos professores de SRM no âmbito de seus municípios, em relação à sua formação. 


\section{METODOLOGIA}

Utilizou-se como instrumento um questionário on-line (survey), o qual foi enviado a professores das SRM em âmbito nacional por meio do site do Observatório Nacional de Educação Especial - ONEESP. O survey foi elaborado tomando como base "falas reais" de professores de SRM, coletadas nos municípios de Rio Claro-SP, São Carlos-SP, Feira de Santana-BA, Catalão-GO e Marília-SP. Tais falas foram coletadas por meio de grupos focais, em que se discutiram com os professores aspectos relacionados ao funcionamento das SRM.

A partir desse corpus de dados, a construção do instrumento foi feita por meio dos seguintes procedimentos:

a. compatibilização dos cinco em um único sistema de categorização;

b. seleção de excertos de falas reais representativas de cada categoria para compor itens do questionário;

c. criação de um objetivo a ser atendido por cada questão formulada;

d. definição do sistema de resposta: após discussão entre pesquisadores optou-se pelo questionário de tipo likert;

e. submissão a juízes para validação de conteúdo;

f. aplicação do piloto a professores de SRM para validação semântica.

Depois de realizadas as adaptações sugeridas pelos juízes e pelos professores que participaram da aplicação do questionário piloto, o questionário foi inserido em um site ${ }^{1}$ para acesso dos professores de SRM de todo o Brasil.

O recrutamento dos professores de SRM foi feito pelos pesquisadores envolvidos na rede do ONEESP, com divulgação que continha instruções sobre como ter acesso ao endereço eletrônico. Ao acessar o site do questionário, os participantes assinavam um termo de consentimento livre e esclarecido e, a partir disso, tinham acesso às questões.

O survey contém 84 questões no total, das quais 12 requerem informações sobre o professor, envolvendo nome, data de nascimento, local de atuação, formação e experiência. Em seguida, dispõe 68 questões em escala likert para respostas: "concordo totalmente", "concordo parcialmente", "nem concordo/nem discordo", "discordo parcialmente" e "discordo totalmente". No final, possui quatro questões abertas para que o professor deixe um recado para seus alunos, para os pais de seus alunos, para a escola e para os políticos. O questionário foi aplicado em larga escala, coletaramse dados de 1202 professores de SRM das redes municipais de ensino de 20 estados em mais de 150 cidades. A aplicação em larga escala é um fator importante, pois traz dados relativos a diferentes regiões brasileiras.

\section{RESULTADOS E DISCUSSÃO}

Elaborou-se uma série de questões que visaram a conhecer os aspectos relacionados à formação do professor que atua na SRM. Organizaram-se 
as questões de forma discursiva, com apoio de figuras para melhor visualização dos dados. As respostas foram discutidas considerando a legislação e a literatura relacionada ao tema.

A Figura 1 apresenta as porcentagens das diferentes respostas dadas pelos participantes considerando se o professor que atua na SRM está preparado para lidar com a diversidade de alunos com necessidades educacionais específicas.

FIGURA 1

PORCENTAGEM DE CONCORDÂNCIA DOS PROFESSORES SOBRE SUA PREPARAÇÃO PARA ATUAR COM AS DIVERSIDADES DO PAEE

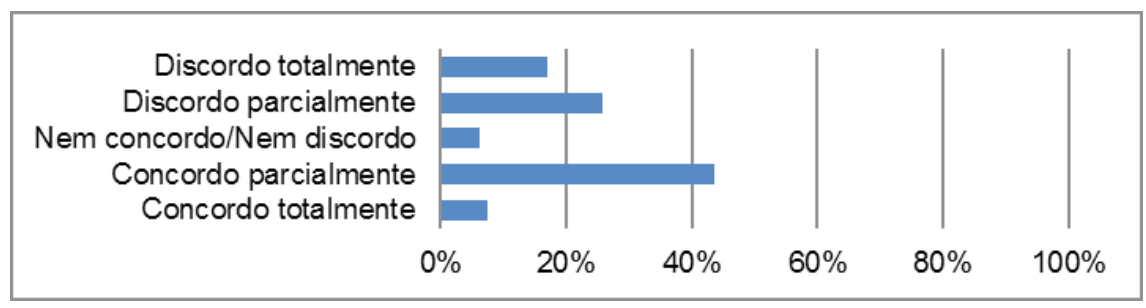

Fonte: Elaboração das autoras.

A atual política de inclusão escolar prevê o AEE como modelo de atendimento aos alunos da educação especial, o qual deve ser ofertado nas SRM. Dentro desse contexto, o professor deve atuar, no contraturno, com os alunos considerados PAEE. Segundo a legislação (BRASIL, 2008a), os alunos PAEE consistem naqueles com deficiência (física, auditiva, visual ou intelectual), transtornos globais do desenvolvimento - TGD - e/ou altas habilidades/superdotação - AH/SD. Nesse sentido, é necessário verificar se o professor que atua na SRM está preparado para lidar com tamanha diversidade de alunos com necessidades educacionais específicas.

A Figura 1 mostra que pouco mais da metade dos participantes respondeu positivamente, sendo que mais de $40 \%$ das respostas positivas foi de concordância parcial. Observa-se que apenas 7,5\% dos participantes apontaram sentirem-se completamente aptos, enquanto 43,6\% disseram sentirem-se parcialmente aptos. Nota-se uma divisão de opiniões, mas fica evidente que poucos relatam estarem totalmente aptos. Para que esse perfil seja melhorado, é preciso investimento na formação inicial e continuada do professor de educação especial, com oferta de cursos de capacitação para que venham a atender às necessidades da diversidade dos PAEE (MENDES; CAPELLINI, 2007; PASIAN; MENDES; CIA, 2012; PRIETO, 2006). Também é preciso investir na realização de intervenções colaborativas advindas do contexto real das necessidades dos professores para a criação de cursos de especialização e de formação continuada (OLIVEIRA, 2010; PRIETO; PAGNEZ; GONZALES, 2014; VITALIANO; MANZINI, 2010).

Outro aspecto avaliado no questionário é ilustrado na Figura 2, que mostra as respostas dos docentes sobre se há dificuldade em compreender a 
função do AEE de complementar para os alunos com deficiência e TGD e de suplementar para os alunos com AH/SD.

\section{FIGURA 2}

PORCENTAGEM DE CONCORDÂNCIA DOS PROFESSORES SOBRE DIFICULDADE EM COMPREENDER A FUNÇÃO DO AEE DE COMPLEMENTAR E DE SUPLEMENTAR

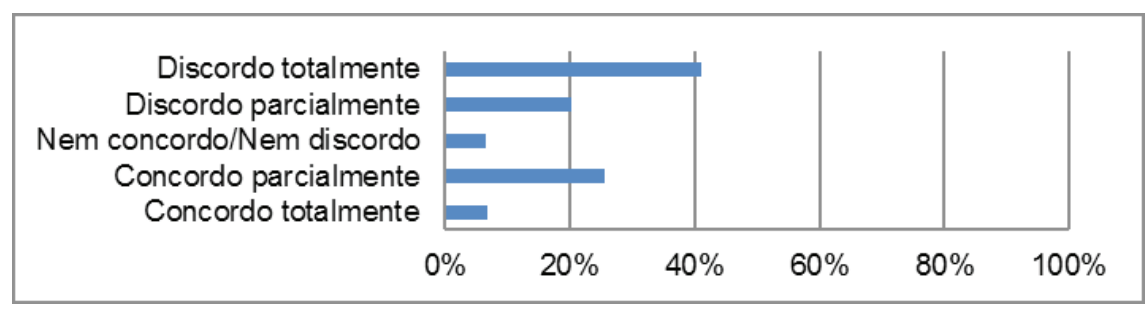

Fonte: Elaboração das autoras.

Constata-se que 61,4\% declararam não possuir dificuldade em compreender a função do AEE de complementar para os alunos com deficiência e TGD e suplementar para os alunos com AH/SD. Apesar de a maioria dos docentes ter apontado que não sente dificuldade, 32,2\% destacaram possuir dificuldade. Essa é uma barreira muito grande, pois se o professor não compreende a função que deve desempenhar, como irá realizá-la com êxito?

Faz-se necessário que os docentes possuam acesso ao material destinado a elucidar o caráter do atendimento para cada alunado específico, bem como à legislação. Nesse sentido, a Figura 3 traz as respostas dos professores ao questionamento sobre seu acesso aos documentos orientadores da SRM/AEE publicados pelo MEC.

FIGURA 3

PORCENTAGEM DE CONCORDÂNCIA DOS PROFESSORES SOBRE ACESSO AOS DOCUMENTOS ORIENTADORES DA SRM/AEE PUBLICADOS PELO MEC

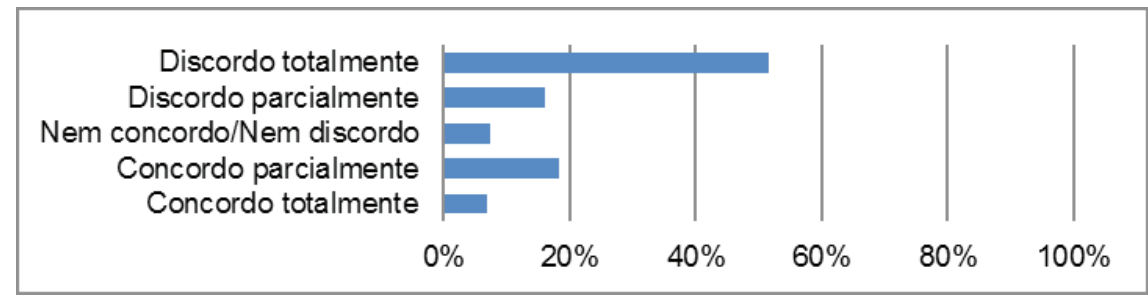

Fonte: Elaboração das autoras.

Pode ser observado que um quarto dos participantes respondeu não ter acesso aos documentos orientadores da SRM/AEE publicados pelo MEC. Segundo o art. 12 da Resolução CNE/CEB n. 4/2009, o professor, para atuar no AEE, deve possuir formação inicial em licenciatura e formação específica em educação especial (BRASIL, 2009). Novamente focamos em investimentos na formação do professor, que deveria conhecer a função do AEE, pois atua na mesma. Apenas dois cursos de graduação 
em educação especial são oferecidos em universidades federais brasileiras (Universidade Federal de São Carlos - UFSCar - e Universidade Federal de Santa Maria - UFSM) e a maioria dos professores que trabalha na SRM possui graduação em pedagogia.

O professor de educação especial precisa conhecer e entender os documentos que orientam seu trabalho na SRM/AEE, a fim de auxiliá-lo na sua execução. Dessa forma, cursos de formação continuada são importantes para oferecer-lhes tal subsídio (PASIAN; MENDES; CIA, 2012; PRIETO, 2006; VITALIANO; MANZINI, 2010). Ainda no que tange à atuação desses docentes, a Figura 4 mostra suas respostas sobre o trabalho na SRM em todos os níveis de ensino.
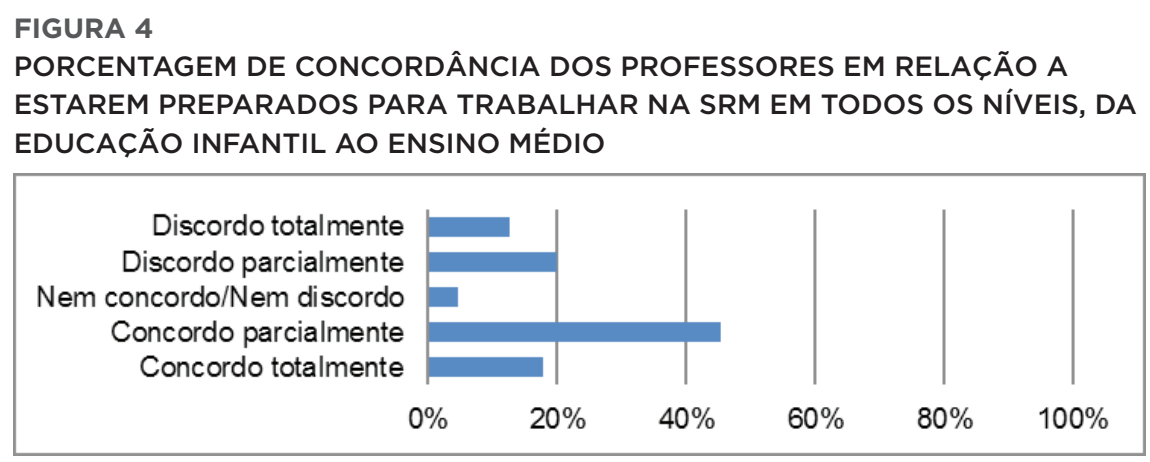

Fonte: Elaboração das autoras.

A Figura 4 mostra que a maioria dos professores (61\%) respondeu estar preparada para trabalhar em todos os níveis de ensino e pouco mais de 30\% afirmaram não estarem preparados para tal. Essas respostas levantam o questionamento sobre alternativas que podem ser investigadas futuramente, como o que falta para que todos possam atuar em todos os níveis e o que é proporcionado em sua formação para se sentirem aptos.

É interessante salientar que os professores sentem-se preparados para atuar em todos os níveis, uma vez que as demandas para cada nível de ensino são bem diferenciadas. Neste estudo não foi possível verificar em que condições esses professores atuam, ou mesmo se eles atendem alunos do mesmo nível de ensino ou não, dado que as principais queixas dos professores é a de atender vários alunos de níveis de ensino diferentes (MENDES et al., 2010; PLETSCH, 2009).

Na Figura 5, é relatado se mais prática docente e formação podem dar condições de ensinar qualquer tipo de aluno PAEE. 
FIGURA 5

PORCENTAGEM DE CONCORDÂNCIA DOS PROFESSORES EM RELAÇÃO A SE A PRÁTICA DOCENTE E FORMAÇÃO OFERECEM CONDIÇÕES DE ENSINAR QUALQUER TIPO DE ALUNO PAEE

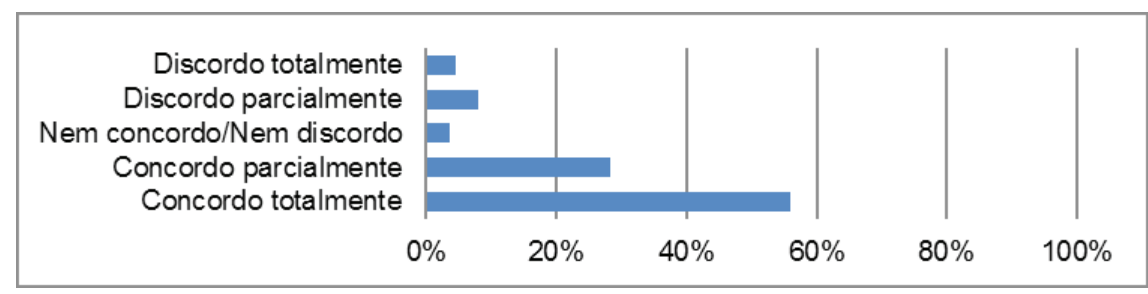

Fonte: Elaboração das autoras.

Observa-se, na Figura 5, que a maioria dos participantes $(84,1 \%)$ respondeu positivamente. Apesar de os professores defenderem que, com mais experiência docente e formação estariam aptos a lidar com todos os alunos PAEE, respondem negativamente ao serem questionados se um único profissional é capaz de atuar com todas as especificidades que aparecem para serem atendidas na SRM (Figura 6, abaixo). Provavelmente isso ocorre porque, atualmente, esses professores não se veem preparados para lidar com todas as necessidades dos alunados e atribuem essa dificuldade à má formação ou pouca formação, ou mesmo à falta de experiência. A Figura 6 mostra a opinião dos professores a respeito de serem capazes de atuar com as especificidades do alunado nas SRM.

FIGURA 6

PORCENTAGEM DE CONCORDÂNCIA DOS PROFESSORES SOBRE UM PROFESSOR SER CAPAZ DE ATUAR COM TODAS AS ESPECIFICIDADES QUE APARECEREM PARA SEREM ATENDIDAS NA SRM

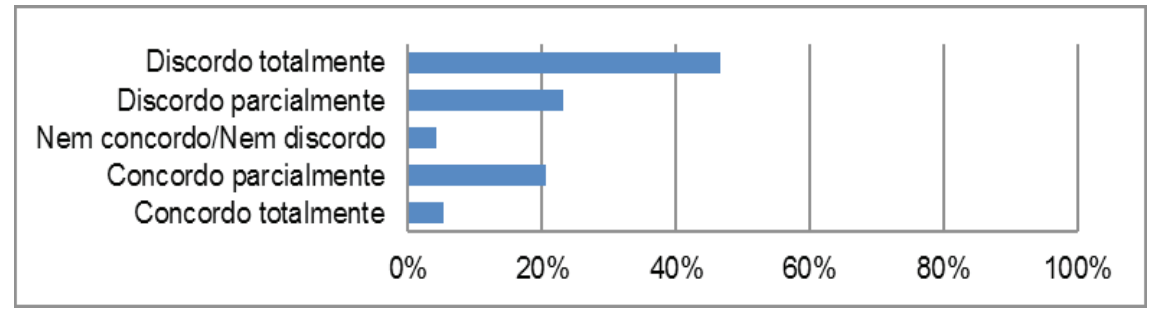

Fonte: Elaboração das autoras.

Constata-se, na Figura 6, que 69,9\% das respostas foram negativas. Somente $4,2 \%$ dos participantes se mantiveram neutros e $25,8 \%$ responderam positivamente. Logo, pode-se inferir que a maioria dos participantes acredita que é necessário mais de um profissional. Mas, afinal, que formação deve existir para atender a tais especificidades? Bueno (1999) defende a combinação de dois profissionais: o generalista e o especialista. O primeiro, com pouco conhecimento e prática com alunos especiais e o segundo, com conhecimento aprofundado e prática sistemática (PLETSCH, 2009). 
A formação do professor especialista seria generalizada, havendo aprimoramentos específicos que tornariam possível ao professor realizar a função de atendimento especializado. Mas, acima de tudo, esse professor teria como papel auxiliar o professor da classe comum (PLETSCH, 2009). Sobre essa mesma temática, Ferreira (1999) defende que a formação do professor de educação especial não deve ser especialista, mas sim focada para atuar com a diversidade. Omote (2003), por sua vez, também não concorda com uma formação especialista, mas que seja rearranjada a formação específica, com foco para as necessidades como dificuldades de comunicação e inserção no mercado de trabalho, por exemplo.

Oliveira (2010) aponta que é errôneo desconsiderar certos quadros de deficiência, bem como conhecimentos específicos demandados para prover qualidade de ensino para determinados alunos e que podem não estar disponíveis para todos os professores. Além disso, a autora também destaca o fato de que uma formação específica em educação especial não elimina a necessidade de haver formação para todos os docentes dentro de uma perspectiva inclusiva.

A partir do momento que há um conjunto de especificidades que demandam conhecimentos para atuar com um determinado alunado, faz-se necessário que docentes possuam formação adequada para tal, e essa formação necessita ser específica para que o professor seja capaz de potencializar o aprendizado de seus alunos, provendo o melhor ensino possível para eles. Quanto à formação necessária para atuar na SRM, a Figura 7 mostra que a maior parte dos participantes acredita que esse profissional precisa, além de possuir a graduação, ser especialista em diferentes categorias.

FIGURA 7

PORCENTAGEM DE CONCORDÂNCIA DOS PROFESSORES EM RELAÇÃO À NECESSIDADE DE O PROFESSOR DE SRM SER GRADUADO E ESPECIALISTA EM DIFERENTES CATEGORIAS

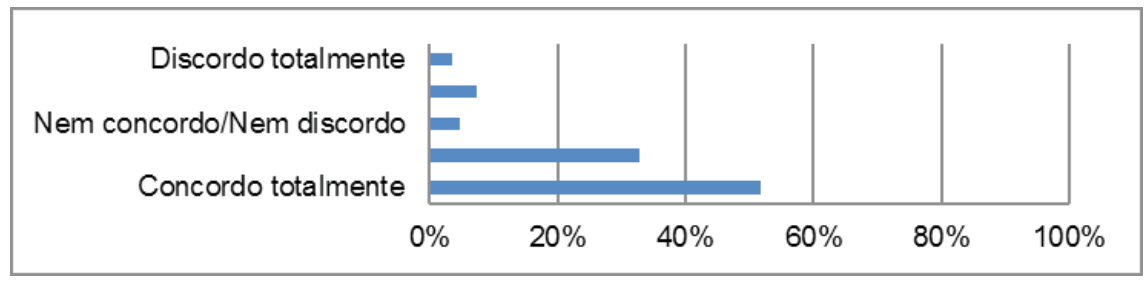

Fonte: Elaboração das autoras.

Através dessa questão, verificou-se que a maioria dos participantes $(84,5 \%)$ apontou que há necessidade de ser especialista em diferentes categorias. Essas respostas reafirmam a necessidade de o professor de SRM realizar formação continuada e ter habilitações que possibilitem a melhora de seu trabalho no AEE.

Quanto à capacitação geral, questionou-se se o professor da SRM deve ter capacitações e ensinar todos os tipos de alunos PAEE (Figura 8). 
FIGURA 8

PORCENTAGEM DE CONCORDÂNCIA DOS PROFESSORES EM RELAÇÃO À NECESSIDADE DE TER CAPACITAÇÕES PARA ENSINAR TODOS OS ALUNOS PAEE

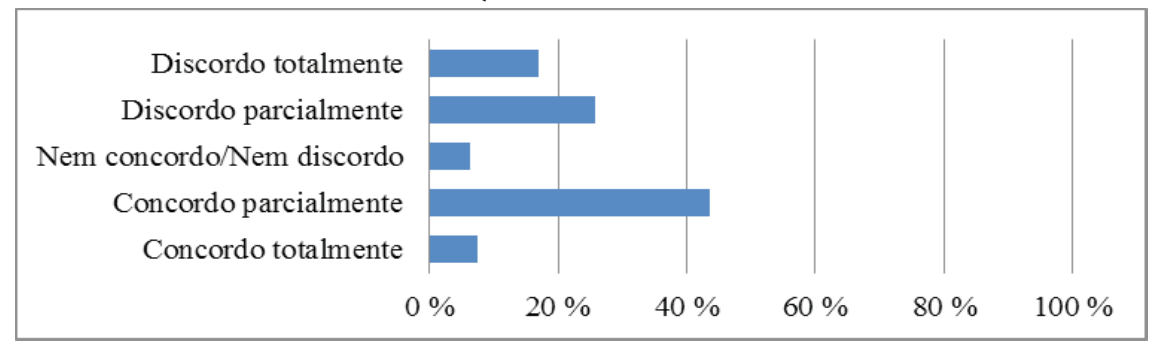

Fonte: Elaboração das autoras.

Essa foi a questão em que houve maior balanceamento entre as respostas. Ainda assim, a maioria (58,3\%) respondeu positivamente e $38 \%$ responderam negativamente. Pode-se verificar que a maior parte dos docentes defende a necessidade de haver um profissional especializado para determinada deficiência atuando na SRM, ao mesmo tempo que o profissional existente atualmente demanda capacitação em diferentes categorias, capacitação esta que deve ser para todas as categorias: deficiências, TGD e AH/SD (PASIAN; MENDES; CIA, 2012; PRIETO, 2006; VITALIANO; MANZINI, 2010).

Vem à tona, novamente, a necessidade de se debater sobre formação inicial e continuada dos docentes de SRM. A próxima questão, ilustrada na Figura 9, é sobre a formação inicial.

FIGURA 9

PORCENTAGEM DE CONCORDÂNCIA DOS PROFESSORES SOBRE A SUPERFICIALIDADE DAS INFORMAÇÕES REFERENTES À INCLUSÃO ESCOLAR E À EDUCAÇÃO ESPECIAL DURANTE A GRADUAÇÃO

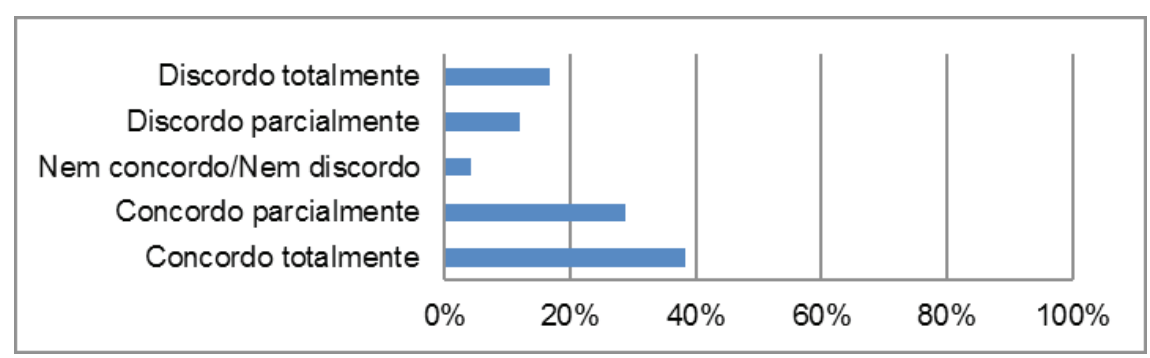

Fonte: Elaboração das autoras.

Observa-se que a maioria dos participantes concordou que as temáticas de inclusão escolar e de educação especial foram tratadas de forma superficial. No que tange à discussão acerca da formação inicial de profissionais para atuar na educação especial, Pletsch (2009) aponta que, no geral, não há preparação necessária nas licenciaturas de modo que estas permitam formar professores que saibam como atuar com a realidade colocada pela inclusão. 
Mendes et al. (2010) apontam que é indispensável possibilitar formação inicial em educação especial por meio da criação de cursos de licenciatura cujo foco esteja nos conhecimentos específicos nessa área. Tal possibilidade vai de encontro às respostas dos professores, que demandam mais formação e especificidade. Ao mesmo tempo, é preciso levar em consideração, como já mencionado, que existem apenas duas universidades que oferecem esse modelo de formação, a UFSM e a UFSCar. Sendo assim, é preciso criar possibilidades de formação continuada que minimizem as dificuldades encontradas pelos professores, para que os alunos PAEE tenham o melhor aprendizado possível.

Ainda com foco na formação inicial, buscou-se averiguar a relação da formação inicial com a prática. Para tal, questionou-se se a base teórica que os docentes possuíam na área de educação especial era suficiente para trabalhar na prática (Figura 10).

\section{FIGURA 10}

PORCENTAGEM DE CONCORDÂNCIA DOS PROFESSORES SOBRE POSSUIR UMA BASE TEÓRICA NA ÁREA DE EDUCAÇÃO ESPECIAL INSUFICIENTE PARA TRABALHAR NA PRÁTICA DA SRM

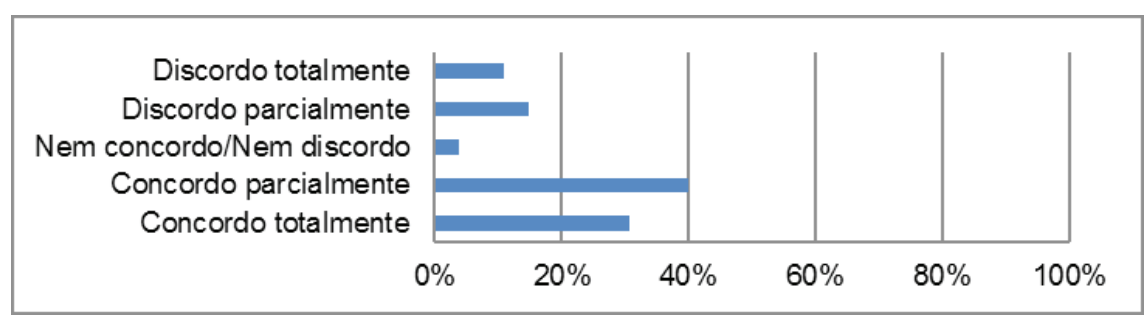

Fonte: Elaboração das autoras.

Quanto às exigências previstas para que um docente possa atuar no AEE, elas se resumem à necessidade de o docente possuir formação inicial em licenciatura e formação específica em educação especial (BRASIL, 2009). Essa formação atende às necessidades dessa função? Os resultados revelados na Figura 10 demonstram que 70,6\% dos participantes (a maioria, portanto) consideram a base teórica que possuem atualmente insuficiente para atuar na SRM. Faz-se necessário investir na formação continuada, averiguar se os docentes estão buscando aprimorar seus respectivos conhecimentos sobre a área e o alunado e facilitar esse aprimoramento.

Dando continuidade a esse tópico, questionou-se, como se vê nas figuras 11 e 12, se os participantes conseguem realizar cursos baseados nas necessidades específicas de seus alunos e se os cursos realizados ajudaram para seu trabalho docente. 


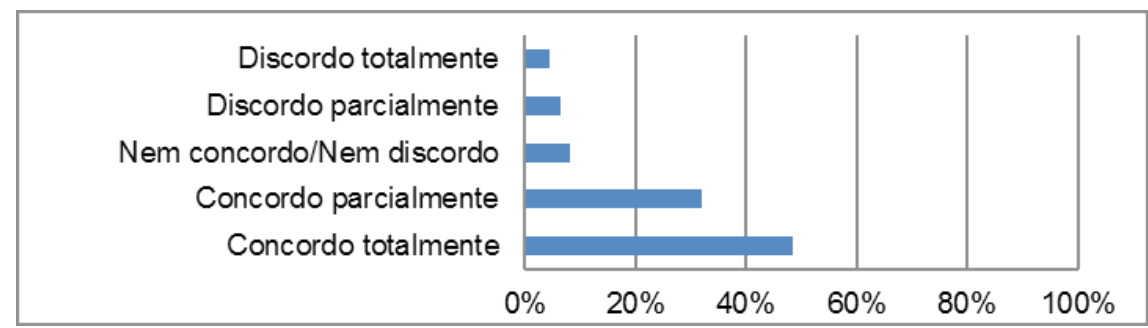

Fonte: Elaboração das autoras.

FIGURA 12

PORCENTAGEM DE CONCORDÂNCIA DOS PROFESSORES SOBRE A REALIZAÇÃO DE CURSOS QUE AJUDARAM A EXERCER SUA FUNÇÃO VINCULADA ÀS SUAS NECESSIDADES COMO PROFESSORES

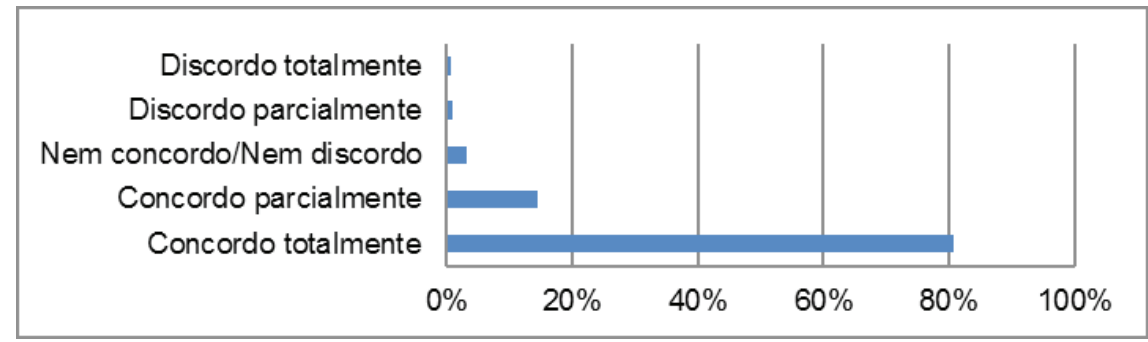

Fonte: Elaboração das autoras.

A Figura 11 mostra que a maioria dos docentes respondeu positivamente. Destes, 48,6\% concordam totalmente e 32,1\%, parcialmente. Resultado semelhante é observado na Figura 12, em que 95,1\% dos professores responderam positivamente à pergunta feita. Isso vem ao encontro de vários estudos que afirmam que intervenções colaborativas para conhecer as necessidades dos cursos a serem oferecidos aos professores são positivas para a melhora do seu trabalho como professor no AEE (OLIVEIRA, 2010; PRIETO; PAGNEZ; GONZALES, 2014; VITALIANO; MANZINI, 2010).

A formação do professor para trabalhar com o PAEE deve ser efetiva para capacitá-lo e especializá-lo para atender às necessidades educacionais dos alunos, favorecendo a inclusão escolar. Também devem ser ofertados cursos de formação continuada aos professores, de acordo com suas necessidades, para melhorar a qualidade do ensino (BRASIL, 1996, 2001; PASIAN MENDES; CIA, 2014; PRIETO, 2006).

Outro aspecto bastante recorrente revelado pela pesquisa foi a necessidade de buscar informações com professores mais experientes para complementar a formação dos docentes (Figura 13). 


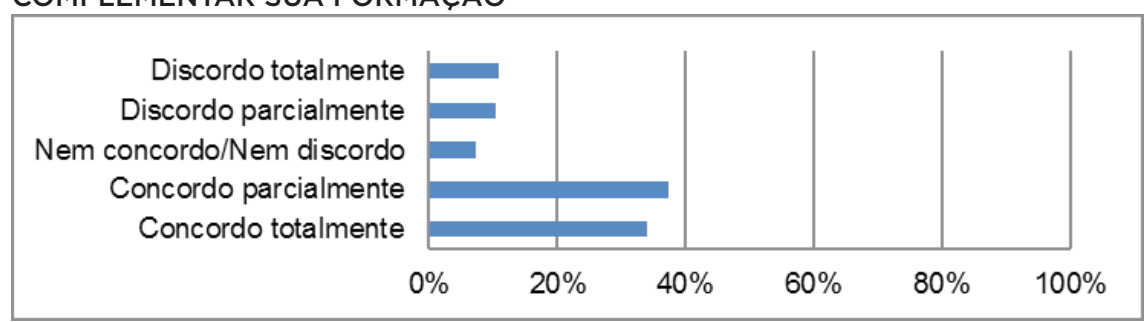

Fonte: Elaboração das autoras.

Constata-se que $71,4 \%$ das respostas foram positivas, das quais $34,1 \%$ dos professores concordam totalmente e 37,3\% concordam parcialmente. Oliveira (2010) destaca que a formação em educação especial precisa ser repensada. Uma vez que não há uma política que contemple a formação inicial em educação especial, é preciso refletir sobre de que maneira será realizada a formação através de cursos de curta duração. Segundo os dados desse estudo, pode-se perceber que os participantes buscam, na formação continuada e, logo, nos cursos de curta duração, um caminho para sanar suas dificuldades. Mas será que esses cursos são suficientes para que o docente adquira os conhecimentos a que não teve acesso em sua formação inicial?

Um estudo do ONEESP, realizado a partir das falas de professores de SRM, apontou que é preciso que haja formação continuada para que haja mudanças. De fato, várias professoras participantes do grupo focal não se sentiam preparadas para atuar com todo tipo de aluno PAEE (CARNEIRO; DALL'ACQUA; ZANIOLO, 2014).

Quanto ao incentivo para realizar formação continuada, a Figura 14 apresenta a questão de se os participantes concordam em serem chamados para cursos e capacitações e de serem, com isso, incentivados a buscar formação continuada por parte da escola.

FIGURA 14

PORCENTAGEM DE CONCORDÂNCIA DOS PROFESSORES SOBRE SEREM CHAMADOS PARA CURSOS E CAPACITAÇÕES

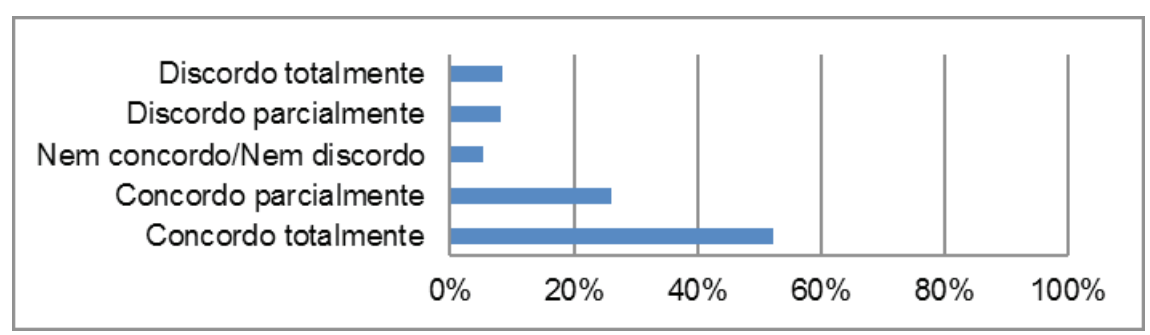

Fonte: Elaboração das autoras. 
Verifica-se que a maioria dos professores (78,3\%) são chamados para realizar cursos e capacitações, sendo que 52,3\% dos participantes concordam totalmente e $26 \%$ concordam parcialmente. Ainda dentro das demandas de formação dos participantes, questionou-se se estes necessitam de formação no que tange a trabalhar em colaboração com os outros professores da escola. A grande maioria $(81,4 \%)$ respondeu positivamente. O trabalho de continuidade na formação e a troca de experiências com outros profissionais mostram-se positivos no contexto educacional e na melhora da qualidade de ensino perante a grande diversidade do alunado do AEE (PASIAN; MENDES; CIA, 2014; PRIETO, 2006). Como relatado por Pletsch (2009), faz-se necessário elaborar políticas públicas educacionais voltadas para práticas inclusivas e ofertar cursos de formação de professores que os auxiliem a compreender e a agir nas situações de diversidade das exigências educacionais e, consequentemente, na educação inclusiva.

Outra questão levantada, que diz respeito à colaboração, foi se, no horário de trabalho coletivo da escola dos participantes, estes tinham tempo de discutir com outros professores sobre os alunos da SRM. Notou-se que $65,4 \%$ dos docentes responderam possuir esse tempo, sendo que $24,4 \%$ concordaram totalmente e $41 \%$ concordaram parcialmente.

A seguir, a Tabela 1 traz informações sobre o sentimento dos professores da SRM no que tange à valorização de seu trabalho.

TABELA 1

PORCENTAGEM DE CONCORDÂNCIA DOS PROFESSORES SOBRE A VALORIZAÇÃO DE SEU TRABALHO EM RELAÇÃO A OUTROS PROFISSIONAIS DA ESCOLA E ÀS FAMÍLIAS DE ALUNOS PAEE

\begin{tabular}{l|c|c|c|c|c}
\hline \multicolumn{1}{|c|}{$/$} & $\begin{array}{c}\text { CONCORDO } \\
\text { TOTAL }\end{array}$ & $\begin{array}{c}\text { CONCORDO } \\
\text { PARCIAL }\end{array}$ & $\begin{array}{c}\text { NEM } \\
\text { CONCORDO/ } \\
\text { NEM DISCORDO }\end{array}$ & $\begin{array}{c}\text { DISCORDO } \\
\text { PARCIAL }\end{array}$ & $\begin{array}{c}\text { DISCORDO } \\
\text { TOTAL }\end{array}$ \\
\hline $\begin{array}{l}\text { Profissionais } \\
\text { da escola }\end{array}$ & $23,5 \%$ & $44,8 \%$ & $7,7 \%$ & $15,8 \%$ & $8,2 \%$ \\
\hline Família & $45,9 \%$ & $41,3 \%$ & $5,1 \%$ & $6,9 \%$ & $0,8 \%$ \\
\hline
\end{tabular}

Fonte: Elaboração das autoras.

Dados que implicam diretamente nas duas questões, elucidadas na Tabela 1, consistem no sentimento desses professores da SRM no que tange à valorização de seu trabalho, bem como se eles se sentem ou não sozinhos. As resposta tanto quanto à sua valorização por parte de outros profissionais da escola quanto por parte da família foram positivas, com $68,3 \%$ e $87,2 \%$ de respostas positivas, respectivamente. Apesar do alto índice de sentimento positivo de valorização, quando questionados se sentem-se solitários na condução do trabalho na SRM, a maioria dos docentes $(60,1 \%)$ respondeu positivamente, somente $7,9 \%$ se manteve neutro e $32,1 \%$ respondeu negativamente.

Dall'Acqua e Vitaliano (2010) apontam que os professores da classe comum não foram preparados para atuar com os alunos PAEE e 
que, com isso, é frequente que esses professores sintam-se estressados com a presença desses alunos, havendo sentimento de impotência e outras decorrências negativas.

Dentro do âmbito da formação dos professores da classe comum:

[...] é unânime a constatação de que os professores não estão preparados para incluir alunos com NEE, ${ }^{2}$ seus cursos de graduação não os prepararam para isso e as poucas oportunidades de formação continuada também não. (VITALIANO; MANZINI, 2010, p. 51)

Há, com isso, a necessidade de se pensar com urgência cursos de formação para que os professores da classe comum assumam a responsabilidade pela educação de todos os alunos (VITALIANO; MANZINI, 2010), pois, uma vez que os professores da classe comum não sentem os alunos PAEE como sendo seus alunos e defendem que não foram preparados para atuar com esse público - e, de fato, normalmente não o foram -, fica difícil haver um sentimento de parceria com o professor da SRM de forma que este se sinta menos solitário em seu trabalho.

Ao mesmo tempo, é compreensível que os professores da SRM sintam que são reconhecidos por parte de outros profissionais da escola. Muitos professores da sala comum reconhecem a dificuldade de trabalhar com a diversidade do PAEE e contam com apoio do trabalho do professor do AEE.

\section{CONSIDERAÇÕES FINAIS}

Ao observar as funções destinadas ao professor da SRM, percebe-se que elas são diversas, demandando conhecimento sobre todas as categorias de alunos PAEE. Os professores do AEE precisam ter articulação com os docentes da classe comum e fornecer orientação às famílias. Além disso, há necessidade de confeccionar recursos pedagógicos para o desenvolvimento de atividades na SRM. As respostas dos professores apontaram para uma visão otimista em relação à sua formação, bem como para a possibilidade de atender um alunado tão distinto.

Apesar disso, a maioria dos participantes destacou haver a necessidade de mais de um profissional na SRM, bem como cerca da metade dos participantes apontou não se sentir preparado para atuar efetivamente com os alunos que são encaminhados para a SRM. A formação continuada mostrou-se a alternativa mais destacada pelos profissionais a fim de buscar aprimoramento de seus conhecimentos.

Pode-se alertar o mesmo que ressalta Pletsch (2009), ou seja, que, para ocorrerem mudanças efetivas no quadro educacional brasileiro em relação à inclusão de alunos com necessidades especiais, é preciso combater os problemas educacionais gerais. A formação inicial e continuada dos 
professores torna-se fundamental para a melhora da qualidade do ensino, seja na educação como um todo, seja no AEE. A proposta de inclusão e o atendimento do PAEE devem ser articulados com a adequação e a melhoria da capacitação dos profissionais da educação brasileira como um todo.

\section{REFERÊNCIAS}

BRASIL. Lei n. 9.394, de 20 de dezembro de 1996. Estabelece as diretrizes e bases da educação nacional. Diário Oficial [da] República Federativa do Brasil, Brasília, DF, 23 dez. 1996. Seção 1.

BRASIL. Conselho Nacional de Educação. Câmara de Educação Básica. Resolução CNE/CEB n. 2, de 11 de setembro de 2001. Brasília: CNE/CEB, 2001.

BRASIL. Política de educação especial na perspectiva da educação inclusiva. Brasília, DF: Ministério da Educação/SEE, 2008a. Disponível em: <http://portal.mec.gov.br/arquivos/pdf/ politicaeducespecial.pdf>. Acesso em: 15 mar. 2015.

BRASIL. Decreto n. 6.571, de 17 de setembro de 2008. Dispõe sobre o atendimento educacional especializado, regulamenta o parágrafo único do art. 60 da Lei n. 9.394, de 20 de dezembro de 1996, e acrescenta dispositivo ao Decreto n. 6.253, de 13 de novembro de 2007. Diário Oficial [da] República Federativa do Brasil, Brasília, 18 set. 2008b.

BRASIL. Ministério da Educação. Conselho Nacional de Educação. Resolução nº 04, de 2 de outubro de 2009. Institui as Diretrizes Operacionais para o Atendimento Educacional Especializado na Educação Básica - Modalidade Educação Especial. Diário Oficial [da] República Federativa do Brasil, Brasília, DF, 5 out. 2009.

BRASIL. Decreto n. 7.611. Dispõe sobre a educação especial, o atendimento educacional especializado e dá outras providências. Diário Oficial [da] República Federativa do Brasil, Brasília, 17 nov. de 2011.

BUENO, J. G. Crianças com necessidades educativas especiais, política educacional e a formação de professores: generalistas ou especialistas. Revista Brasileira de Educação Especial, Marília, v. 3, n. 5 , p. 7-25, 1999.

CARNEIRO, R. U. B.; DALL'ACQUA, M. J. C.; ZANIOLO, J. A Formação de professores especializados e inclusão escolar: contribuições para o debate de uma experiência do Observatório Nacional de Educação Especial - ONEESP. In: ENCONTRO DO OBSERVATÓRIO NACIONAL DE EDUCAÇÃO ESPECIAL, 4., 1994. São Paulo. Anais... São Paulo, 2014. p. 1-14.

DALL'ACQUA, M. J. C.; VITALIANO, C. R. Algumas reflexões sobre o processo de inclusão em nosso contexto educacional. In: VITALIANO, C. R. (Org.). Formação de professores para a inclusão de alunos com necessidades educacionais especiais. Londrina: Eduel, 2010. p. 19-30.

FERNANDEZ, J. A. T. Organización de la escuela para la sociedade multicultural. In: JORNADAS NACIONALES DE UNIVERSIDAD Y EDUCACIÓN ESPECIAL, 15., 1998, Oviedo. Anais... Oviedo: Universidad de Oviedo, 1998. v. 1, p. 59-90.

FERREIRA, M. C. C. Construindo um projeto político-pedagógico para a formação de educadores no contexto da educação especial. In: BICUDO, M. A. V.; SILVA JUNIOR, C. A. (Org.) Formação do educador e avaliação educacional. São Paulo: Editora Unesp, 1999. p. 139-148.

KASSAR, M. C. M. Política de educação especial no Brasil: escolha de caminhos. In: MENDES, E. G.; ALMEIDA, M. (Org.). A pesquisa sobre inclusão escolar em suas múltiplas dimensões: teoria, política e formação. Marília, SP: ABPEE, 2012. v. 1, p. 93-106.

MENDES, E. G. A radicalização do debate sobre inclusão escolar no Brasil. Revista Brasileira de Educação, Rio de Janeiro, v. 11, n. 33, p. 387-405, 2006.

MENDES, E. G.; CAPELLINI, V. L. M. F. O ensino colaborativo favorecendo o desenvolvimento profissional para a inclusão escolar. Educere et Educere, Cascavel, v. 2, n. 4, p. 113-128, 2007.

MENDES, E. G. et al. Professores de educação especial e a perspectiva da inclusão escolar: uma nova proposta de formação. In: MENDES E. G.; ALMEIDA, M. (Org.). Das margens ao centro: perspectivas para as políticas e práticas educacionais no contexto da educação especial inclusiva. Araraquara: Junqueira \& Marin, 2010. p. 61-78. 
OLIVEIRA, A. A. S. Inclusão escolar e formação de professores: o embate entre o geral e o especifico. In: MENDES, E. G.; ALMEIDA, M. A. (Org.). Das margens ao centro: perspectivas para as políticas e práticas educacionais no contexto da educação especial inclusiva. Araraquara: Junqueira \& Marin, 2010. p. 61-78.

OMOTE, S. A formação do professor de educação especial na perspectiva da inclusão. In: BARBOSA, R. L. L. Formação de educadores: desafios e perspectivas. São Paulo: Editora Unesp, 2003. p. $153-169$.

PASIAN, M. S.; VELTRONE, A. A.; CAETANO, N. C. S. P. Avaliações educacionais e seus resultados: revelando ou omitindo a realidade brasileira sobre o fracasso escolar. Revista Eletrônica de Educação, São Carlos, SP, v. 6, p. 440-456, 2012.

PASIAN, M. S.; MENDES, E.G.; CIA, F. O funcionamento pedagógico nas salas de recursos multifuncionais: revisão de trabalhos em eventos científicos. Cadernos da FUCAMP, Campinas, v. 12, p. 17-27, 2012.

PASIAN, M. S.; MENDES, E. G.; CIA, F. Salas de recursos multifuncionais: revisão de artigos científicos. Revista Eletrônica de Educação, São Carlos, SP, v. 8, n. 3, p. 213-225, 2014.

PRIETO, R. G. Atendimento escolar de alunos com necessidades educacionais especiais: um olhar sobre as políticas públicas de educação no Brasil. In: ARANTES, V. A. (Org.). Inclusão escolar: pontos e contrapontos. São Paulo: Summus, 2006. p. 31-73.

PRIETO, R. G. Políticas de Inclusão Escolar no Brasil: sobre novos/velhos significados para educação especial. In: MENDES, E.; ALMEIDA, M. (Org.). Das margens ao centro: perspectivas para as políticas e práticas educacionais no contexto da educação especial inclusiva. Araraquara: Junqueira \& Marin, 2010. p. 61-78.

PRIETO; R. G.; PAGNEZ, K. S. M. M.; GONZALES, R. K. Educação especial e inclusão escolar: tramas de uma política em implantação. Educação \& Realidade, Porto Alegre, v. 39, n. 3, p. $725-743,2014$.

PLETSCH, M. D. A formação de professores para a educação inclusiva: legislação, diretrizes políticas e resultados de pesquisas. Educar em Revista, Curitiba, n. 33, p. 143-156, 2009.

VITALIANO, C. R.; MANZINI, E. J. A formação inicial de professores para inclusão de alunos com necessidades educacionais especiais. In: VITALIANO, C. R. (Org.). Formação de professores para a inclusão de alunos com necessidades educacionais especiais. Londrina: Eduel, 2010. p. 49-112.

VITALIANO, C. R.; VALENTE, S. M. P. A formação de professores reflexivos como condição necessária para inclusão de alunos com necessidades educacionais especiais. In: VITALIANO, C. R. (Org.). Formação de professores para a inclusão de alunos com necessidades educacionais especiais. Londrina: Eduel, 2010. p. 31-48.

\author{
MARA SILVIA PASIAN \\ Universidade Federal de São Carlos - UFSCar -, São Carlos, São Paulo, Brasil \\ marasilvia123@yahoo.com.br
}

ENICÉIA GONÇALVES MENDES

Universidade Federal de São Carlos - UFSCar -, São Carlos, São Paulo, Brasil egmendes@ufscar.br

\title{
FABIANA CIA
}

Universidade Federal de São Carlos - UFSCar -, São Carlos, São Paulo, Brasil fabianacia@hotmail.com 